\title{
There is a time and a place for everything: Bidirectional modulations of latent inhibition by time-induced context differentiation
}

\author{
R. E. LUBOW \\ Tel Aviv University, Ramat Aviv, Israel \\ and \\ L. G. DE LA CASA \\ University of Seville, Seville, Spain
}

\begin{abstract}
Latent inhibition (LI) is defined as poorer evidence of learning with a stimulus that previously was presented without consequence, as compared with a novel or previously attended stimulus. The present article reviews the evidence, mostly from three-stage conditioned taste aversion studies (preexposure, conditioning, and test), that LI can be either attenuated or enhanced depending on the length of the retention interval between conditioning and test and where that interval was spent. Time-induced reduction in $\mathrm{LI}$ is observed when the interval context is the same as that of the preexposure, conditioning, and test stages. Super-LI is obtained when a long retention interval is spent in a context that is different from that of the other stages. The differential modulations of LI appear to be the result of the strengthening of primacy effects (i.e., first training disproportionately stronger than subsequent training) by long-interval different contexts, thereby producing super-LI, and the reversal of this effect by long-interval same contexts, thereby producing attenuated LI. The bidirectional effects of time/ context modulations on LI, unaccounted for by current learning theories, are explained, in part, by a time-induced context differentiation process. Implications for theories of LI, learning, and memory are discussed.
\end{abstract}

Time is a sort of river of passing events, and strong is its current; no sooner is a thing brought to sight than it is swept by and another takes its place, and this too will be swept away. (Marcus Aurelius, Meditations [trans. 1964], iv. 43)

That memory is a function of time is a truism. Indeed, what is memory but some present mark of a past event. Most commonly, as time between study and test increases, memory performance decreases, a situation that we call forgetting. Sometimes, however, memory improves over time, as with reminiscence (an increase with repeated testing), hypermnesia (increased recall), and incubation.

Context, too, has profound effects on memory. In humans, for example, local context can disambiguate the meaning of a word (see, e.g., Kintsch \& Mross, 1985), and more global or tonic contexts, when changed from learning to subsequent test sessions, can result in relatively poor memory performance (e.g., Smith, Glenberg, \& Bjork, 1978). The effects of context on memory have been extensively studied also with animals, as in habituation (e.g.,

Preparation of this article was supported by Grant 932/02 from The Israel Science Foundation funded by the Israel Academy of Sciences and Humanities. The authors thank Paul Schnur for his helpful comments on an earlier version of this article. Correspondence concerning this article should be addressed to R. E. Lubow, Department of Psychology, Tel Aviv University, Ramat Aviv 69978, Israel (e-mail: lubow@freud.tau.ac.il).
Hall \& Channell, 1985; Honey, Pye, Lightbrown, Rey, \& Hall, 1992), spontaneous recovery (e.g., Bouton \& Peck, 1989; Harris, Jones, Bailey, \& Westbrook, 2000), latent inhibition (e.g., Lubow, Rifkin, \& Alek, 1976; McLaren, Bennett, Plaisted, Aitken, \& Mackintosh, 1994), and simple conditioning (e.g., Bouton \& King, 1983; for a review of these literatures, see Bouton, 1993; Bouton, Nelson, \& Rosas, 1999). Irrespective of the particular research domain, the usual explanation of context-based effects incorporates some version of the hypothesis that contextual stimuli serve as retrieval cues for previously learned associations or information.

Recent experiments have demonstrated that context and time appear to be interchangeable (e.g., Bouton, 1993; Bouton et al., 1999), such that time and physical context manipulations have additive effects (e.g., Rosas, Vila, Lugo, \& Lopez, 2001; Westbrook, Jones, Bailey, \& Harris, 2000). To explain this, it has been proposed that with increased time between acquisition and test, there is a gradual change in the internal representation of context. As a consequence, with long intervals, identical acquisition and test contexts become subjectively differentiated (see Estes, 1997; McGeoch, 1942; Mensink \& Raaijmakers, 1988; Spear, 1973, 1978).

Although it has long been recognized that memory is affected by both the passage of time and the relation between acquisition and test contexts, the role of the retention 
interval context has been largely ignored. This neglect has been an unintended and unfortunate outcome of certain customary and, in some cases, unavoidable constraints on experimental procedures, particularly in studies that use relatively long retention intervals. Oddly enough, the procedural constraints in human and animal studies produce opposing implementations of experimental designs. Thus, in experiments with human subjects, long retention intervals, on the order of days or even hours, will not be spent in the same laboratory room as the acquisition and test stages. It is simply not convenient for either the experimenter or the subject to be enclosed in the same context for extended periods of time. Consequently, the typical procedure for studying the effects of long retention intervals on humans uses the same laboratory room for acquisition and test, but the retention interval is spent in an unspecified "elsewhere." This procedure can be denoted as $\mathrm{A}(\mathrm{B}) \mathrm{A}$, where $\mathrm{A}$ is the context of the acquisition and test stages and $\mathrm{B}$ is the context in which the retention interval is spent.

In the analogous animal literature, where the subject has little to say, long retention intervals can be spent in a variety of places. In fact, however, these places are determined by the specific experimental paradigm. Thus, with conditioned taste aversion (CTA), in which conditioning and test stages are easily accomplished in the home cage, the retention interval will also be spent in the home cage. On the other hand, with conditioned suppression, acquisition and test stages require a specially instrumented enclosure for delivering stimuli and measuring responses. Thus, the retention interval will not be spent in that context but, rather, in the home cage. For CTA, then, retention interval experiments take the form of $\mathrm{A}(\mathrm{A}) \mathrm{A}$, and for conditioned suppression, A(B)A.

As will be shown, these procedural differences are far from trivial. Recent CTA experiments on latent inhibition (LI) have demonstrated that the effects of retention interval duration on memory-related performance can be either positive or negative, depending on the relationship of the retention interval context to the contexts in which the remaining experimental procedures are conducted.

\section{THE MODULATION OF LI BY RETENTION INTERVAL DURATION AND CONTEXT}

\section{The LI Effect}

LI is an empirical phenomenon. It is defined as relatively poor performance on a learning task in which one of the currently relevant stimuli had a history of being irrelevant, unattended, or ignored, as compared with the same stimulus when it is novel or it was previously attended (for reviews, see Lubow, 1973, 1989; Lubow \& Gewirtz, 1995). The typical animal LI experiment is composed of three phases-preexposure, acquisition, and test-and at least two groups. One group is preexposed to the target stimulus that will later be paired with an unconditioned stimulus (US) in the acquisition phase. The second group is not preexposed to that stimulus but, otherwise, is treated identically to the preexposed group. In the acquisition phase, both groups receive one or more pairings of the preexposed stimulus with the US. LI is demonstrated in the test phase when the preexposed group exhibits weaker responding to the previously conditioned stimulus than does the nonpreexposed group. Such an effect, exceedingly robust, has been shown with many mammalian species, including humans, and with many different learning paradigms.

LI would seem to be an example of selective processing that economizes on system capacity; it protects the organism from associating random, inconsequential, nonpredictive stimuli with subsequent events by biasing the organism to more fully process new inputs, as opposed to older inconsequential ones. Since its first description by Lubow and Moore (1959), LI has been of interest to experimental psychologists, psychophysiologists, and clinical psychologists. It has had influence on theories of associative learning (e.g., Mackintosh, 1975; Pearce \& Hall, 1980; Wagner, 1981). It also has been the basis for procedures with which to study interference effects in memory (e.g., Bouton, 1993) and for analyzing dysfunctional attentional processes in pathological populations, particularly in schizophrenic patients (e.g., Baruch, Hemsley, \& Gray, 1988a; N. S. Gray, Hemsley, \& Gray, 1992; for reviews, see Lubow, 2005; Lubow \& Kaplan, 2005). Despite its ubiquitousness and its strong claim to adaptive significance, there is considerable controversy concerning its theoretical foundations.

\section{Explanations of $\mathbf{L I}$}

Explanations of LI effects fall into two general categories: attentional decline/acquisition failure (e.g., Lubow, Weiner, \& Schnur, 1981; Mackintosh, 1975; Pearce \& Hall, 1980; Wagner, 1981) and retrieval-based competition (e.g., Bouton, 1993; Miller, Kasprow, \& Schachtman, 1986). The experiments that led to the present article grew out of the disagreement between these two approaches. Is LI the consequence of an attentional process that results in a loss of stimulus associability, or is stimulus associability intact, with LI being the outcome of a retrieval competition process?

Attentional-decline/association-deficit theories of LI assume that passive, inconsequential stimulus preexposure reduces attention to that stimulus. As a consequence, there is a decline in the ability of the stimulus to enter into new associations. The theories differ from each other in regard to what is learned during preexposure and how that learning is transferred to the CS-US acquisition stage (for reviews, see Hall, 1991; Lubow, 1989). As opposed to the acquisition failure theories, it has been proposed that LI results from a retrieval-based competition between associations learned in the preexposure phase (CS-0; i.e., CS-no-consequence; for recent evidence for the acquisition of CS-0, see Killcross \& Balleine, 1996) and in the acquisition phase (CS-US), the latter of which has not 
been affected by preexposure to the CS. Support for the retrieval failure account of LI has come primarily from two types of animal experiments: those that vary the time between acquisition and test phases of three-stage paradigms and those that use reminder treatments before the test stage.

As was noted, the retrieval hypothesis, in direct opposition to the attention/associability deficit hypothesis, proposes that the acquisition of the new association to the previously exposed stimulus proceeds normally. However, in the test stage, when the subject again encounters the stimulus that was preexposed and then conditioned, the two associations acquired in the previous two stages are retrieved and compete for expression. Retrieval theorists hold that if one varies the time between acquisition and test and LI is found after a short, but not after a long, delay, this is evidence that with the short delay, the CS-US association was acquired but not manifest. In other words, something occurred during the longer delay that allowed the normally associated CS-US event from the acquisition phase to be retrieved. There is considerable evidence that is congruent with this position (Aguado, de Brugada, \& Hall, 2001, Experiment 2; Aguado, Symonds, \& Hall, 1994, Experiment 1; Bakner, Strohen, Nordeen, \& Riccio, 1991, Experiments 1 and 2; De la Casa \& Lubow, 1995, Experiment 2). There is also some evidence that the presentation of a reminder stimulus before test alleviates the otherwise expected retarded learning (e.g., Kasprow, Catterson, Schachtman, \& Miller, 1984).

The loss of LI with an increase in retention interval, indeed, appears to support a retrieval competition explanation of LI and to pose a problem for acquisition fail- ure theories. However, the delay-induced attenuation of LI has not been obtained consistently (e.g., Álvarez \& López, 1995, Experiment 2; De la Casa \& Lubow, 2000, 2002, 2005; Lubow \& De la Casa, 2002). A review of the LI CTA retention interval literature suggests an explanation for the disparate results. On the one hand, experiments that report a reduction in LI after the delay were conducted entirely in the animals' home cages, including the retention interval (e.g., Aguado et al., 2001; Bakner et al., 1991). On the other hand, the experiments that obtained intact or enhanced LI used preexposure, conditioning, and test contexts that were different from the delay context (e.g., De la Casa \& Lubow, 2000, 2002; for a complete set of references, see Table 1).

\section{Rationale for Studying Time-Induced Modulations of LI}

On its own, the discrepancy in the literature described above is hardly enough reason to embark on a major research program. However, the ability to account for LI is a prominent feature that differentiates animal learning theories, many of which attempt to explain LI, either explicitly or implicitly, by introducing attentional constructs (e.g., Lubow, 1989; Mackintosh, 1975; Pearce \& Hall, 1980; Wagner, 1981). On this basis, reports showing that LI was reduced in some schizophrenic patient subgroups (e.g., Baruch et al., 1988a; N. S. Gray et al., 1992) and in high-schizotypal normals (e.g., Baruch, Hemsley, \& Gray, 1988b; Lubow, Ingberg-Sachs, Zalstein-Orda, \& Gewirtz, 1992) were seen as manifestations of a dysfunctional attentional process, as would be expected from the well-documented high distractibility of these groups (e.g.,

Table 1

Super, Attenuated, or Unchanged Latent Inhibition (LI) Effects in Conditioned Taste Aversion Experiments as a Function of Retention Interval Duration for Studies in Which the Interval Context Was the Same as [AA(A)A] or Different From [AA(B)A] the Other Experimental Stages

\begin{tabular}{|c|c|c|}
\hline \multirow[b]{2}{*}{ Effect } & \multicolumn{2}{|c|}{ Interval Context } \\
\hline & Same & Different \\
\hline Super-LI & & $\begin{array}{l}\text { De la Casa \& Lubow (2000, Experiments } 1,2, \& 3 \mathrm{~A}) \\
\text { De la Casa \& Lubow }\left(2002 \text {, Experiments } 1^{*} \& 2^{\dagger}\right) \\
\text { De la Casa \& Lubow }(2005 \text {, Experiments } 1 \& 2)^{\ddagger} \\
\text { Lubow \& De la Casa }(2002, \text { Experiment } 1 \mathrm{~A}) \\
\text { Lubow \& De la Casa }(2005)\end{array}$ \\
\hline Attenuated LI & $\begin{array}{l}\text { Aguado, de Brugada, \& Hall (2001, Experiment 2) } \\
\text { Aguado, Symonds, \& Hall (1994, Experiment 1) } \\
\text { Bakner, Strohen, Nordeen, \& Riccio (1991, Experiments } 1 \text { \& 2) } \\
\text { De la Casa \& Lubow (2005, Experiment 1) } \\
\text { Ishii, Yamada, Hishimura, \& Haga (2002, Experiments } 1 \text { \& 2) }\end{array}$ & De la Casa \& Lubow (1995, Experiment 2) \\
\hline Unchanged LI & $\begin{array}{l}\text { De la Casa \& Lubow (2000, Experiment 3B) } \\
\text { Kraemer \& Ossenkopp (1986) } \\
\text { Kraemer \& Roberts (1984, Experiments } 3 \text { \& 4) } \\
\text { Kraemer \& Spear (1992, Experiment 1) } \\
\text { Lubow \& De la Casa (2002, Experiment 1B) } \\
\text { Lubow \& De la Casa (2005) }\end{array}$ & Álvarez \& López (1995, Experiment 2) \\
\hline
\end{tabular}

Note-Identical citations indicate data from the same experiments. *Super-LI was a function of number of flavor preexposures (with four but not two). All other preexposed groups had LI, but there was no difference among them. $†$ There were four delay conditions (1, 7, 14, and 21 days); super-LI was present only with the 21-day delay. $¥$ The procedure involved successive preexposure to two flavors (counterbalanced). Gain or loss of LI refers to the first preexposed flavor. 
Anscombe, 1987; Mirsky \& Duncan, 1986; Nuechterlein \& Dawson, 1984). As a consequence, the attentional/associative deficit model of LI has been widely incorporated into explanations of attentional deficits in schizophrenia (e.g., J. A. Gray, 1998; J. A. Gray, Feldon, Rawlins, Hemsley, \& Smith, 1991; Lubow, 2005; Weiner, 2003). However, more recently, the opposing retrieval competition model has been proposed as an alternative theoretical account of the LI deficits in schizophrenia (Escobar, Oberling, \& Miller, 2002; Oberling, Gosselin, \& Miller, 1998). From this perspective, the reduced LI in schizophrenic patients is the result of their inability to establish associations between the context and the to-be-CS during preexposure, a prerequisite for obtaining LI, as proposed by the comparator hypothesis (e.g., Grahame, Barnet, Gunther, \& Miller, 1994), as well as by other explanations of LI (e.g., Lubow \& Gewirtz, 1995; Wagner, 1981).

Relatedly, there have been a number of clinically related applications of the LI effect. However, these have been primarily prophylactic_-namely, using inconsequential stimulus preexposures in order to prevent, for example, the acquisition of food aversions due to radiation- or chemotherapy-induced nausea or of school or dental phobias (for a review, see Lubow, 1998). On the other hand, the presently described postevent time/context manipulations, which can either decrease or increase LI, have implications for clinical treatment, the effectiveness of which would be strengthened by a theoretical understanding of these effects.

Finally, as was noted in the introduction, the animal CTA preparation provides a unique opportunity to study the effects of long retention intervals under context conditions that cannot be duplicated in memory experiments with human subjects. In human studies, retention manipulations have centered on very short intervals, on the order of seconds and minutes. When the intervals extend to hours and days, they always are spent in contexts that are different from that of acquisition (for reviews of retention interval studies, see Payne, 1987; Rubin \& Wenzel, 1996).

Thus, the animal CTA preparation provides otherwise unavailable information that requires consideration by all theories of memory. However, there is also a conundrum here. Although it is desirable to relate and to generalize our results from the rat CTA studies to other research domains, particularly with humans, it is exactly those special characteristics of the rat CTA preparation that make it difficult to achieve such a goal. Nevertheless, as will be seen below, even here, there has been some progress.

In summary, for reasons described above, it is essential to confront the conflicting patterns of CTA data regarding time-induced modulations of LI and to clarify the mechanisms or rules that relate to the two competing explanations of LI effects. Differentiating between acquisition and retrieval failure theories requires one to (1) specify the variables that modulate LI, (2) identify the associations that are learned during the preexposure phase, and then (3) postulate a mechanism by which these associa- tions modulate test performance. As we have noted elsewhere, there is considerable information regarding the first requirement, but not nearly enough for the second to warrant aspiring to the third (De la Casa \& Lubow, 1995). On this basis, then, we embarked on a series of CTA studies to investigate the role of the interval context on the delay-induced modulation of LI (De la Casa \& Lubow, 2000, 2002, 2005; Lubow \& De la Casa, 2002, 2005; De la Casa, Diaz, \& Lubow, 2003, 2005).

In brief, our studies show that the LI effect increases with an increase in the temporal interval between the Stage 2 acquisition and the Stage 3 test, but only when that interval is spent in a context that is different from that of the other stages (De la Casa \& Lubow, 2000, 2002, 2005; Lubow \& De la Casa, 2002, 2005). Delay-induced super-LI is generated with $\mathrm{AA}(\mathrm{B}) \mathrm{A}$ context conditions; the first letter represents the context of the preexposure stage, the second represents the conditioning stage, the third, with brackets, represents the context in which the interval is spent, and the fourth represents the context of the test stage. Thus, for $\mathrm{AA}(\mathrm{B}) \mathrm{A}$, the preexposure, acquisition, and test are conducted in the same context-namely, $\mathrm{A}$ - and the interval is spent in a different context, (B). As opposed to the $\mathrm{AA}(\mathrm{B}) \mathrm{A}$ procedure, which results in timeinduced super-LI, other investigators have routinely found that the $\mathrm{BB}(\mathrm{B}) \mathrm{B}$ condition, in which the retention interval is spent in the same context as that of the other stages (usually all in the home cage), generates attenuated LI (e.g., Aguado et al., 1994). This time $\times$ context interaction is clearly seen in Table $1 .{ }^{1}$ With the AA(B)A condition, 9 of 11 experiments produced super-LI (1 experiment showed no difference in LI, and 1 a gain in LI with increase in retention interval). With the AA(A)A condition, 0 of 14 experiments produced super-LI (7 experiments showed a loss of LI with an increase in retention interval, and 7 showed no difference in LI).

\section{DATA RELATED TO EXPLAINING THE DELAY-INDUCED MODULATIONS OF LI}

The pattern of results, as described in Table 1, that requires an explanation relates to the fact that CTA-derived delay-induced changes in LI take two forms: LI is attenuated when the long delay is spent in the same context as that of the other experimental stages, and LI is potentiated when the long delay is spent in a different context from that of the other experimental stages. A comprehensive explanation of the context-dependent, time-induced modulations of LI must, of course, account for the effects of the time and context variables themselves. In addition, however, the explanation must address the roles of (1) two, as opposed to one, pretest associations, (2) the motivational relationship between the CS-0 and the CS-US association, (3) the order of acquisition of the two associations, and (4) the effects of variables, such as numbers of preexposures and US intensity, that independently increase LI and conditioning, respectively. 


\section{One or Two Associations?}

The first question is whether the time/context manipulations affect LI by modulating only one of the two nominal associations, CS- 0 or CS-US. This can be ascertained, at least in part, by examining the effects of the time/context variables on Stages 1 (CS-0) and 2 (CS-US) of the LI procedure, but separately from each other, as in habituation of neophobia (only CS-0 presentations) and in simple conditioning experiments (only CS-US presentations).

Habituation of flavor neophobia. Preexposure of a novel flavor reduces the initial tendency to avoid that flavor. Once flavor neophobia has been diminished, the introduction of a long delay interval between the last CS-0 habituation trial and the CS-0 test trial, even within the wide range of from 2 to 96 days, does not affect the recovery of the habituated response (Aguado et al., 1994; Best, Domjan, \& Haskins, 1978). In addition, retention is not affected by the relationship of the delay context to the preexposure and test stage contexts. Thus, Best et al. found no difference in the amount of target flavor consumed after a 96-day delay, as compared with a 2-day delay, in the A(B)A condition. Other studies have reported similar results for delays varying from 1 to 24 days in the B(B)B condition (Aguado et al., 1994; Kaye, Gambini, \& Mackintosh, 1988; Kraemer \& Roberts, 1984; Siegel, 1974; in all of the above cases, B was the home cage). Using the same basic parameter values as in their superLI experiments, De la Casa, Diaz, and Lubow (2003, Experiment 1) showed that when saccharin preexposure preceded the interval and context manipulations, habituation of flavor neophobia was strengthened by an increase in the retention interval, but independently of the context in which the interval was spent. Thus, in conjunction with the context-dependent super-LI studies, it would appear that there is a dissociation between LI and habituation. Such a conclusion also has been reported with other preparations (Hall \& Channell, 1985; Hall \& Honey, 1989; Hall \& Schachtman, 1987).

Simple conditioning. Although super-LI might be explained by a decrease in CS-US strength as a function of length of the retention interval, CTA is, if anything, stronger after long than after short postconditioning delays. This phenomenon, the retention interval effect (RIE), has been demonstrated over a wide range of intervals (e.g., Batsell \& Best, 1993, 1994; Biederman, Milgram, Heighington, Stockman, \& O’Neill, 1974; Steinert, Infurna, \& Spear, 1980). However, the size of the effect does not increase beyond the first few days of delay (e.g., Batsell \& Best, 1992b). With only two exceptions, experiments that have reported an RIE were executed such that all stages-conditioning, interval, and test-were conducted in the home cages. Batsell and Best (1992a, Experiment 6) specifically compared the effects of retention intervals ( 1 and 6 days) when the intervals were spent in contexts different from or the same as those of the other experimental stages. The RIE was present in the same, but not in the different, context condition. Using longer retention intervals ( 1 vs. 21 days), De la Casa et al. (2003, Experiment 2) produced an RIE in both of the delay context conditions.

In short, CTA is not attenuated by long, as opposed to short, retention intervals. In fact, it appears to increase as a function of retention interval length, at least when the retention interval context is the same as that of the other contexts. Consequently, by itself, a reduction in CS-US strength as a function of retention interval duration cannot account for the super-LI effect.

Summary. The fact that each of the two pretest components of the delay-induced modulations of LI (CS-0 and CS-US), when presented separately, yielded effects that were independent of interval context precludes explanations of the delay-induced modulations of LI that are based on changes in only one of the two associations. In other words, the attenuated LI and super-LI effects, which are interval context dependent, are the results of an interaction between Stage 1 and Stage 2 events, rather than the simple sum of two independent processes.

\section{The Motivational Relationship Between the Two Associations}

Having established that at least two associations are required to account for time/context-modulated LI, the question arises as to whether such effects are limited to the particular case of CS-0 and aversive CS-US associations. However, it must first be noted that the CS-0 designation for the association that is acquired in the stimulus preexposure stage of an LI experiment, although appropriate for most LI paradigms, raises problems for CTA. When a thirsty animal drinks a flavored solution, it is reinforced. Nevertheless, one might argue that the flavor in the preexposure stage of an LI CTA experiment has the same status as a masked preexposed stimulus in a human LI experiment - that is, it is present but relatively unattended (Lubow \& Gewirtz, 1995). Such a position is supported by the finding that frontal lesions, which should disrupt attended behavior, do not affect CTA extinction. This indicates that attention to flavor is relatively weak in a CS-0 condition (Fresquet, Yamamoto, \& Sandner, 2003).

Irrespective of whether CS-0 is the appropriate term for describing preexposure to a flavored fluid, the fact that the same flavor stimulus is presented on one occasion without an overt consequence, and on another occasion it is followed by an aversive US, makes the meaning of that stimulus at the time of test a source of conflicting or ambiguous information (Bouton, 1993, 2002, 2004; Miller et al., 1986; Nelson, 2002; for a cogent analysis of different paradigms representing interference between cues and interference between outcomes, see Miller \& Escobar, 2002). The question, then, is whether such conflict/ambiguity is a necessary condition for producing differences in the expression of context/time-induced performance of two previously learned associations?

Indeed, experiments whose results are consistent with the conflict/ambiguity position always use associations that 
are conflicting. In a particularly good example, Bouton and Peck (1992) trained animals to acquire two successive associations, tone-shock in the first stage and tone-food in the second stage (or vice versa). The test stage was conducted either 1 or 28 days after the last training. Irrespective of which of the two conflicting association was learned first, recovery of the first association was enhanced with the long, as compared with the short, retention interval (both spent in the home cage). This study, then, provides yet another instance in which a long interval spent in a context that is different from the other experimental contexts promotes the expression of first learning (see the Order of Acquisition of the Two Associations: The Role of Primacy section below). Nevertheless, since ambiguity or conflict of the associations was not manipulated, their specific role in the time-enhanced recovery of the first learned association remained untested.

De la Casa and Lubow (2005) addressed this issue in two experiments in which two nonconflicting associations were acquired in the pretest stages. Animals received separate preexposure sessions to each of two flavors, first to one of the flavors and then to the other. The last preexposure session was followed by conditioning to a compound of the two preexposed flavors. After being assigned to the delay $\times$ context conditions, the subjects were given a two-bottle preference test. One bottle contained the first preexposed flavor, and the other bottle contained the second preexposed flavor. We found a time/context-induced super-LI effect for the first preexposed flavor (see the section on primacy below). These results, then, suggest that motivational conflict or ambiguity of the two pretest associations is not a prerequisite for producing the time/ context-modulated LI effects. However, one might argue that the conflict/ambiguity construct is independent of motivational valence. Instead, it may be a property of any two associations that share either a common cue or a common outcome (see Miller \& Escobar, 2002) or, indeed, of any situation that requires the organism to make a choice (as in our two-bottle test).

\section{Order of Acquisition of the Two Associations: The Role of Primacy}

Demonstrations of delay-induced modulations of LI as a function of retention interval context must, by definition, use a procedure in which $\mathrm{CS}-0$ presentations precede CS-US presentations. Is the interaction between CS-0 and CS-US, as expressed in super-LI, specific to this sequence? Alternatively, as suggested by the primacy principle (Konorski \& Szwejkowska, 1952; see also Bouton, 1993; Lubow, 1989, p. 89; Wickens, Tuber, \& Wickens, 1983) the first association may have a time-induced advantage in any situation that consists of two successively learned associations. Indeed, there is considerable evidence that first learning is disproportionately strong as compared with subsequent training, especially when assessed after long retention intervals (thereby negating the countereffects of recency). ${ }^{2}$ In addition to super-LI, time- induced potentiations of primacy effects have been produced with a variety of learning paradigms, particularly those characterized by interstage interference (but see De la Casa \& Lubow, 2005; Reed, Croft, \& Yeomans, 1996), such as spontaneous recovery (e.g., Brooks \& Bouton, 1993; Rescorla, 1997; Rosas \& Bouton, 1998), counterconditioning (Bouton \& Peck, 1992; Peck \& Bouton, 1990), human verbal-learning interference (e.g., Postman, Stark, \& Fraser, 1968; Underwood, 1948a, 1948b), and animal and human discrimination reversal learning (e.g., Chiszar \& Spear, 1969; Gleitman, 1971; Gordon \& Spear, 1973; Spear et al., 1980; Vila, Romero, \& Rosas, 2002). Once again, when lengthy, the retention intervals were spent in a context different from that of the other stages (for an exception, see Rosas \& Bouton, 1996).

The literature cited above argues against the suggestion that the primacy $\times$ retention interval interaction might be limited to the particular sequence that defines LI-namely, CS-0 followed by CS-US. Indeed, when the two stages are reversed, as in extinction procedures, the passage of time after extinction produces spontaneous recovery (SR), an increase of observed CS-US conditioning strength (e.g., Rosas \& Bouton, 1996). SR, then, also represents the facilitated retrieval of the first association. In short, both super-LI and SR can be described in terms of delay-induced recovery of first associations, CS-0 for LI and CS-US for SR (for recent confirmations of this with conditioned suppression of barpressing, and with human contingency judgments, see Wheeler, Stout, \& Miller, 2004, and Stout, Amundson, \& Miller, in press, respectively). In a related set of experiments, Urushihara, Wheeler, and Miller (2004) demonstrated that even USalone manipulations, presented before or after CS-US presentations, are subject to the effects of pretest delays, such that there is a shift from recency to primacy. Notably, in all of the studies above, unlike in our super-LI experiments, the retention interval context was not a variable. However, in each case, the delay context was different from that of the other stages of the experiment.

Thus, without the De la Casa and Lubow experiments in which the context of the retention interval was varied, one might conclude that order of presentation is a necessary and sufficient condition for enhancing the delay-induced primacy effect. However, as we have demonstrated for LI, these order effects are modulated by the nature of the context in which the delay interval is spent. Super-LI is obtained only when the delay context is different from the remaining experimental contexts; if all of the contexts, including that of delay, are the same, LI is attenuated.

By using interval context (same or different) as a variable to differentially affect delay-induced LI (CS-0 presentations in the first stage), together with a condition in which the CS-0 presentations are in the second stage (extinction procedure), one can disentangle the role of type of stimulus presentation (CS-0 vs. CS-US) from order of presentation in producing the various LI and SR effects. To this end, Lubow and De la Casa (2002) examined LI 
and SR as functions of the delay interval between second and third stages and of the context in which the animals spent the delay. In the LI experiments, the first stage consisted of saccharin or water presentations. In the second stage, rats were conditioned by pairing saccharin with $\mathrm{LiCl}$ (an aversive US). In the SR experiments, the order of the two stages was reversed (conditioning followed by extinction). For the LI and SR experiments, the second stage was followed by a retention interval of either 1 or 21 days and then by a test stage (saccharin alone). As before, super-LI was obtained in the saccharin-preexposed group that spent the long delay in the different context. When the delay was spent in the same context, there was no difference in the amount of LI in the short- and the long-delay groups. On the other hand, there was an SR effect in the long-delay/same-context group, but not in the long-delay/different-context group. However, in Wheeler et al.'s (2004) study with conditioned suppression, in which the interval context was different, the long delay potentiated not only LI, but also SR. As was noted earlier, similar time-induced recency-to-primacy shifts have been reported for other preparations, animals, and humans (see above). In general, these time-induced SR effects come from experiments in which subjects spend the retention interval in a different context. Since interval context is not a variable in these experiments, the possible differential effects of type of interval context on the magnitude of the spontaneous recovery effect cannot be assessed, as they were in Lubow and De la Casa (2002).

Our results suggest that time-induced shifts from recency to primacy are also modulated by retention interval context, such that (1) a different delay context supports recovery of primary-positioned CS-0 associations (super-LI) and (2) a same delay context supports recovery of primary-positioned CS-US events (SR). In both cases, then, the passage of time appears to preferentially favor the retrieval of the first-acquired association. However, the conditions for retrieval are different for the LI and extinction procedures. To obtain super-LI, the delay context has to be different. On the other hand, the Lubow and De la Casa (2002) results from both same and different interval contexts, together with the large number of reports of SR with a different retention interval context (e.g., Brooks \& Bouton, 1993; Rescorla, 1997; Rosas \& Bouton, 1998), suggests that the same interval context might be an even stronger potentiator of SR than the different interval context. Clearly, more research is required to unravel the apparently complex interaction among retention interval context, retention interval duration, order of acquisition of the two (or more) associations, and type of association. As has repeatedly been noted, such an enterprise would be severely hampered by obstacles to collecting data from the long retention interval AA(A)A condition.

\section{The Effects of Number of Stimulus Preexposures and US Intensity}

Super-LI is enhanced by increases in either numbers of stimulus preexposures or US intensity (De la Casa
\& Lubow, 2000, 2002). Despite the fact that the former should strengthen the CS- 0 association and LI and the latter should strengthen the CS-US association and thereby weaken LI, the two variables work in the same directionnamely, to strengthen the super-LI effect. This suggests that super-LI may be enhanced even more by increasing the discriminability of Stage 1 (preexposure) from Stage 2 (conditioning). Interestingly, the well-documented context specificity of LI might lead one to expect exactly the opposite effect, at least in LI procedures with short intervals between preexposure and acquisition stages. On the other hand, with longer retention intervals, differential retrievability may be improved by increasing the discriminability between stages, perhaps by augmenting primacy effects.

\section{THE QUESTION OF GENERALITY}

Since the super-LI effect has been generated primarily from CTA experiments with rats from one laboratory (see Table 1), it is reasonable to ask whether the effect is limited to that specific preparation. To begin with, we will present a summary of the typical procedure used in the nine experiments in Table 1 in which a super-LI effect has been reported. Following this, significant departures from this procedure, still within the framework of CTA, that have been shown to modulate the super-LI effect will be briefly described. In the ensuing paragraphs, we will discuss those studies that have successfully and unsuccessfully reproduced the super-LI effect in protocols other than CTA.

\section{The Typical Procedure for Generating Super-LI}

From the time of their arrival in the laboratory, animals spend at least 3 weeks in their individual home cages before the start of the experiment. On the first 7 days of the experimental regimen, rats in their home cages are placed on a fluid deprivation schedule, with daily access to water for $30 \mathrm{~min}$. All subsequent phases, except for the delay, are conducted in chambers other than the home cages and in a different room from them. For all groups, the preexposure stage takes place from Days 8-11. In this stage, animals in the nonpreexposed group have 5-min access to water on each of the 4 days. Animals in the preexposed group have similar access to a saccharin solution $(0.04 \%)$. On Day 12, all the animals receive one conditioning trial, in which 5-min access to the saccharin solution is followed by a single intraperitoneal (i.p.) injection of $\mathrm{LiCl}$ ( $0.4 \mathrm{M}, 0.5 \%$ bodyweight). The retention interval, either 1 or 21 days between the end of the conditioning trial and the beginning of the first test trial, is spent in the home cage. ${ }^{3}$ On each of the 3 test days, the animal is allowed a 5 -min access to the saccharin solution.

\section{Modulations of Super-LI in CTA by Manipulations of Parameter Values and Variables}

Many of these studies have been alluded to in the Data Related to Explaining the Delay-Induced Modulations of LI section. Using the basic procedures described above, 
LI has been found to increase with numbers of flavor preexposures (0, 2, or 4; De la Casa \& Lubow, 2002, Experiment 1$)$, US intensity $(0.5 \%$ bodyweight i.p. injection of 0.1 M LiCl, and 0.5 M LiCl; De la Casa \& Lubow, 2000), and retention interval duration $(1,7,14$, or 21 days; De la Casa \& Lubow, 2002, Experiment 2). To the extent that these effects are orderly and can be related to theoretical considerations, they also lend support to the generality of the effect, at least within the CTA paradigm.

The most serious threat to the generality of the super-LI effect comes from the manner in which the early experiments manipulated the retention interval context. As can be seen from the summary of the typical procedure, the $\mathrm{AA}(\mathrm{A}) \mathrm{A}$ and $\mathrm{AA}(\mathrm{B}) \mathrm{A}$ retention interval context conditions can be redescribed as $\mathrm{HH}(\mathrm{H}) \mathrm{H}$ and $\mathrm{AA}(\mathrm{H}) \mathrm{A}$, where $\mathrm{H}$ is the home cage. To determine whether the super-LI effect was specific to the condition in which the home cage was the different context, De la Casa and Lubow (2005) conducted a $2 \times 2 \times 2$ (preexposure $\times$ delay $\times$ context) CTA LI experiment in which the retention interval contexts for the context-different groups were not only different from the contexts of the other experimental stages, as in our previous studies, but also different from the home cage context.

During the 3 weeks prior to the experiment, half of the animals were housed in one context, and half in another context (counterbalanced). The two contexts were differentiated on the basis of location (different rooms), cage size, bedding, and ambient lighting. All the animals had preexposure, conditioning, and testing in the same context in which they were housed. During the retention interval, half of animals remained in the same context as that of the other stages, and the other half were placed in a different context from that of the other stages. Thus, the experiment was conducted such that the different retention interval context was not only different from the contexts of the other experimental stages, but also different from the home cage context. We still obtained super-LI, thereby confirming that delay-induced super-LI is not limited to the case in which animals in the different context condition spend the retention interval in their home cages.

In summary, the evidence presented above indicates that the super-LI effect is not limited to a specific CTA procedure. Of course, this says nothing in regard to generalization beyond the CTA paradigm.

\section{Super-LI With Non-CTA Paradigms}

As has been noted, there are a number of constraints that interfere with a full replication of a $2 \times 2 \times 2$ design, particularly in regard to using the long-interval/samecontext condition. Nevertheless, two studies have replicated the results from the conditions that define super-LInamely, with stimulus preexposure and nonpreexposure crossed with long and short retention intervals, but with retention intervals spent only in a different context (Stout et al., in press; Wheeler et al., 2004). Importantly, both studies significantly departed from the CTA protocol.

Wheeler et al. (2004), using 3- and 27-day delays, obtained super-LI with a procedure designed to maxi- mize LI and to minimize ceiling effects (see below). Following the acquisition of water-reinforced leverpressing, there were three training stages, a retention interval, and a test. In the preexposure stage, animals were presented with either unpaired tones or clicks (counterbalanced; $X=$ preexposed stimulus, $\mathrm{Y}=$ nonpreexposed stimulus). For both groups, this was followed by a sensory preconditioning stage in which $\mathrm{X}$ was paired with a flashing light. In the third stage, again for both groups, the light was paired with shock. Testing, preceded by reestablishment of leverpressing, occurred either 3 or 27 days (spent in the home cage) after the light-shock pairings. A test trial consisted of the presentation of $\mathrm{X}$ while the animal was barpressing for water. Thus, the amount of response suppression is an index of the degree to which the animal learned the X-light association. The nonpreexposed groups exhibited more suppression than did the preexposed groups (the LI effect), and the stimulus-preexposed/long-retention-interval group exhibited more LI than did the stimulus-preexposed/shortretention-interval groups (the super-LI effect).

In a related experiment, but with human subjects, Stout et al. (in press) provided groups with one of three two-stage treatments. They received a stage in which stimulus-alone trials were followed by a stage of stimulus-US pairings (LI), the reverse, with stimulus-US pairings followed by stimulus-alone presentations (extinction), or two stages in which an equal number of stimulus-alone and stimulus-US trials were intermixed (partial reinforcement). In all cases, the stimulus was either a red inverted-U or a blue square, and the US was a picture of a human infant. The numbers of reinforced trials (10) and unreinforced trials (10) were the same for the three procedures. Each of the three groups was tested either immediately or $48 \mathrm{~h}$ after the last trial of the second stage. In the test, the subjects were presented with the stimulus that was used in the previous stages, and they were asked, "What is the probability that the baby will follow next?" As was predicted, and in line with the super-LI effects reported with the animal CTA preparation, the predictive ratings of the LI groups were affected by the retention interval manipulation. The 48-h delay group showed significantly more LI than did the no-delay group (i.e., the long-delay group had lower expectations than did the short-delay group that the stimulus would be followed by the US). On the other hand, retention interval duration did not affect the contingency judgment responses of the partial reinforcement group. For the extinction group, the retention interval effects were opposite to that of the LI group; the short-delay group had lower expectations of the US than did the long-delay group. Together, these results suggest a time-induced recency-to-primacy shift.

In summary, the Wheeler et al. (2004) and Stout et al. (in press) experiments provide important evidence for super-LI effects beyond the CTA preparation, the former with conditioned suppression in rats, and the latter with contingency judgments with humans.

\section{Failures to Obtain Super-LI}

In a number of animal studies, procedures other than CTA have been used to investigate the effects of acquisition- 
test retention interval on LI. However, as in the previous section, none of these has been used to examine the interaction of retention interval duration and retention interval context. In non-CTA experiments in which the simple effects of retention interval duration on LI have been examined, always with the AA(B)A condition, a variety of learning paradigms have been used, including conditioned suppression (Bouton \& Brooks, 1993; Wheeler et al., 2004), conditioned freezing (Killcross, Kiernan, Dwyer, \& Westbrook, 1998; Kraemer, Randall, \& Carbary, 1991; Otto, Cousens, \& Rajewski, 1997; Westbrook et al., 2000), and appetitive conditioning (Hall \& Schachtman, 1987; Rosas \& Bouton, 1997). Unlike in our experiments, in which the AA(B)A condition produced super-LI, some of these studies have reported a reduction of LI as a function of an increase in retention interval (Killcross et al., 1998; Kraemer et al., 1991; Westbrook et al., 2000). ${ }^{4}$

Although these data might suggest that the super-LI effect is limited to CTA, there are several reasons to doubt such a conclusion. First, in all three studies cited above, a conditioned freezing procedure was used, opening the possibility that it is their results that are procedure specific. Relatedly, De la Casa, Diaz, and Lubow (2005) examined the effects of retention interval on LI with a conditioned suppression procedure. Using the AA(B)A condition, they found a decrease in LI in a 10-day, as compared with a 2-day, interval with an increase in CS-US strength (one vs. two CS-shock pairings). The reduced LI was due to ceiling effects induced by fear incubation in the groups with the stronger US. Arguably, the attenuated LI reported in the freezing studies also may be due to fearincubated ceiling effects.

More directly, each of these freezing studies differed significantly from the basic design that we used. Thus, in Westbrook et al. (2000, Experiments 4A and 4B), preexposure and acquisition were conducted in different contexts. The test context was either the same as that of preexposure or different from both the preexposure and the acquisition contexts. In Killcross et al. (1998), the context was the CS, thereby precluding any explanations of their data based on CS-context associations, as we have proposed below. In the third study (Kraemer et al., 1991), the preexposure and conditioning stage procedures were conducted with groups of 3 animals, who were then tested individually. Thus, unlike in our experiments, the test context was different from the preexposure and conditioning context, a condition that, by itself, attenuates LI.

\section{Conclusions Regarding Generality}

As can be seen from the data and discussion above, the issue of the generality of super-LI is not easily resolved. On the one hand, the effect is robust and reliable, at least with the CTA protocol. On the other hand, there have been only two experiments that have replicated the basic effect with non-CTA procedures (Stout et al., in press; Wheeler et al., 2004) and a number of studies in which conditions have nominally been used that would, by our account, be expected to generate super-LI but, in fact, did not. In re- gard to these two groups of experiments, it is important to note that in the former, procedures were used that were explicitly designed to test for super-LI, whereas the latter were conducted prior to the discovery of the super-LI effect. Consequently, as has been described, in the latter studies conditions were used that significantly deviated from the ones necessary to induce the super-LI effect.

In short, although there is evidence to support the generality of the time-induced retention interval context effect, the assertion of such generality would benefit from additional research. However, for reasons already notednamely, the inability to impose the long-retention-interval/ same-context condition on human subjects and the practical difficulty of doing so with subhuman organisms, except with the CTA paradigm-it is not likely that direct confirmation of the empirical generality of the complete interaction will be easily forthcoming. It is precisely for this reason, together with the fact that, if generalizable, the reported phenomena would have significant theoretical and practical implications, that a testable explanatory account of these effects is required.

\section{A THEORETICAL FRAMEWORK}

In the previous sections, the effects of number, relation, and order of associations on the context/time-induced modulations of LI were linked to other empirical findings. The present section introduces theoretical formulations, some admittedly speculative, to explain the influence of the time $\times$ context interaction on LI magnitude.

\section{Retention Interval Duration}

Riccio (e.g., Riccio, Ackil, \& Burch-Vernon, 1992; Riccio, Rabinowitz, \& Axelrod, 1994; Riccio, Richardson, \& Ebner, 1984) has argued that many effects that increase with interval time, such as the loss or weakening of a previously acquired discrimination, can be accounted for by a flattening of stimulus generalization gradients over time. Such a flattening would result in the loss of differentiation between specific stimulus features. On the other hand, Bouton and colleagues (e.g., Bouton, 1991,1993; Bouton et al., 1999) have claimed that the retrieval failure that is exhibited after extended retention intervals is the result of such intervals producing context change (internal and/or external). Although both positions can explain the loss of LI with increased retention intervals between acquisition and test stages, neither one can explain why the delay, when spent in a different context, produces a super-LI effect. In short, both Riccio's and Bouton's positions in regard to the effects of time and context on the performance of a previously acquired response are incomplete; they do not take into account the relationship of the context of the retention interval to that of the other experimental stages.

Miller's comparator hypothesis also considers LI to be the result of retrieval failure at time of testing (e.g., Grahame et al., 1994; Miller et al., 1986; Miller \& Matzel, 1988). It proposes that the strength of the conditioned response (CR) to a CS is the result of a comparison, at the 
time of testing, between the associative strengths of the $\mathrm{CS}$ and the context in which the CS was preexposed. More specifically, CR strength in a Stage 3 test is determined by three acquired associations: CS-training context, CS-US, and US-training context. In the test stage, the CS evokes a directly activated representation of the US (CS-US link) and an indirectly activated representation of the same US that is mediated by the comparator stimulus (any stimulus different from the CS that is present during training — in this case, the context). The difference between the directly and the indirectly activated representations of the US by the CS determines the strength of the CR; the former promotes responding, and the latter no responding. As applied to LI, the hypothesis treats context as the comparator stimulus, because the CS-alone presentations in the presence of the context produce a CS-context association. At the time of testing, the CS directly activates a strong representation of the US. Similarly, the indirectly activated representation of the same US by the context also will be strong, due to the representation of the context elicited by the CS. As a result of the comparison between both strong US representations, the CR will be relatively weak-that is, there will be an LI effect (Grahame et al., 1994). From this perspective, repeated presentations of the same context after preexposure, or after preexposure and conditioning, should extinguish the CS-context association (see also Wagner, 1981). Thus, with a longer retention interval in that same context, the CR to the CS should increase (reduced LI). However, as with the other theories, the comparator hypothesis neither makes an explicit prediction nor can it account for the results from the condition in which the long delay is spent in a context that is different from the other experimental contexts-namely, the super-LI effect.

The effects of retention interval duration on LI cannot be explained without first understanding the role of the context in which that time was spent.

\section{Retention Interval Context}

If the context of the retention interval is critical for delay-modulated LI effects, some aspect of context must also be important in the preexposure and/or conditioning stage. Indeed, organisms can acquire CS-context associations during the preexposure stage, as is illustrated by the strong context specificity of the LI effect (e.g., Lovibond, Preston, \& Mackintosh, 1984; Lubow et al., 1976) and by the fact that LI is attenuated when the context in which CS-0 was acquired is subsequently exposed by itself, thereby extinguishing the CS-context association (e.g., Escobar, Arcediano, \& Miller, 2002; Grahame et al., 1994). It would appear, then, that the preexposed context, when present in the test, can serve as a retrieval cue for the CS-0 association that was formed during the preexposure stage (Bouton, 1993; Miller \& Escobar, 2002). Importantly, such context specificity is characteristic of CS-0 conditions. Both LI and extinction are more sensitive than conditioning to context change (e.g., Bouton \&
King, 1983; Bouton \& Peck, 1989; Harris et al., 2000; Westbrook et al., 2000).

\section{The Retention Interval Duration $\times$ Retention Interval Context Interaction}

Thus, we begin the theoretical analysis of the interaction with the generally accepted assumption that in Stage 1, the stimulus-preexposed group acquires a CS-0 association, which, in turn, is associated with the context in which such preexposure occurred. These associations are absent in the nonpreexposed group. In Stage 2, both groups acquire a CS-US association (for the moment, we will ignore whether or not the strength of that association is the same for the two groups); and for both groups, the CS-US association is relatively context independent. When the context of the acquisition-test retention interval is the same as that of the preexposure stage, the CS-context association undergoes an extinction process, the output of which becomes cumulatively stronger with increasing time in that context. As a result, when the organism enters the test stage, again with the same context, the CS-US association dominates the CS-0 association, and LI is weaker after a long than after a short retention interval. This, then, describes the time-induced LI attenuation that has been repeatedly reported when all stages of the experiment, including the retention interval, are conducted in the same context (see Table 1).

This interpretation also is supported by the SR data. When the long interval after extinction is spent in the same context, but not in a different context, there is a strong SR effect (Lubow \& De la Casa, 2002, Experiment 2B; but see Wheeler et al., 2004). Presumably, the CS-0 association acquired during the extinction session, but not the context-independent CS-US association, is extinguished when the retention interval context is the same as the other contexts, exactly as in the LI preparation. On the other hand, the different extended interval context would maintain the CS-context association by not providing conditions for its extinction; and as would be expected from this analysis, SR is attenuated under these conditions (at least when the effects of type of interval contexts are compared directly). Similarly, as we have consistently found, there is greater delay-induced LI when the interval context is different, as opposed to same.

Notably absent from this analysis is an explanation for the facts that, with the different interval context, LI is greater after a long than after a short interval, and with the same context, SR is greater after a long than after a short interval. In other words, we have primarily addressed the source of differences between different types of contexts, but we have not directly confronted the effects of time within a particular context condition.

\section{The Context Differentiation Hypothesis}

As was noted earlier, the effects of context and time manipulations appear to be interchangeable (e.g., Bouton, 1993; Bouton et al., 1999) and additive (e.g., Rosas 
et al., 2001; Westbrook et al., 2000). To explain this, it has been proposed that the internal representation of context changes with increased time between acquisition and test. Thus, with long retention intervals, objectively identical acquisition and test contexts become subjectively differentiated (see Estes, 1997; McGeoch, 1942; Mensink \& Raaijmakers, 1988; Spear, 1973, 1978).

However, the formulations above do not address the relationship between the retention interval context and the other experimental contexts, nor could they have anticipated the type of effects that we report here. To account for the bidirectional effects of the context $\times$ time interaction, we developed the context differentiation hypothesis. The hypothesis proposes that the perceived similarity of CS-0 and CS-US contexts to the test context is a function not only of their physical similarity, but also of the length of the retention interval and the objective similarity of the retention interval context to the other contexts. If the retention interval context is the same as the other contexts, then, with an increase in retention interval, the CS-context association is extinguished, the result of which is attenuated LI and potentiated SR, as has already been discussed. However, we propose that if the retention interval context is different from the other contexts, then, with an increase in retention interval, the perceived similarity of those contexts is increased. As a consequence, the ability of the test context to serve as a retrieval cue for the CS-0 association is strengthened, the result of which is potentiated LI and attenuated SR, the exact opposite of what is obtained with a retention interval context that is the same as that of the other contexts. The facts that, in most of our experiments, the delay intervals (B) were spent in an unsurpassingly familiar home cage and the times spent in the preexposure and acquisition contexts were relatively short may have served to even further enhance the perceived similarity between As in the AA(B)A paradigm by providing an additional dimension for perceived similarity among Asnamely, novelty. 5

It is proposed, then, that if an organism remains in the same context for an extended period of time, that context becomes increasingly partitioned; that is, different epochs (preexposure, conditioning, and test) become progressively more dissimilar from each other. Since LI is reduced when there are different preexposure and test contexts (e.g., Lovibond et al., 1984; Lubow et al., 1976), the conditions that produce context differentiation should reduce LI, either by itself, because with time there is an increase in the perceived difference between the preexposure and the test contexts, or in conjunction with the extinction of the CS-context association. On the reverse side of the context differentiation process, an extended retention interval spent in a context different from that of preexposure and test (which are objectively the same) should increase the perceived similarity of the latter two contexts, thereby promoting retrieval of the context-dependent CS-0 association (as opposed to the retrieval of the relatively contextinsensitive CS-US association) and thus supporting more LI. Relatedly, the same two processes would increase and decrease the perceived similarity between the preexposure and the conditioning contexts.

The context differentiation hypothesis presumes some mechanism that relates to perceptual learning, the wellknown effect by which preexposure to stimuli results in better discrimination among them. According to one class of perceptual-learning theories, repeated presentations of an array of stimuli results in the subject's becoming increasingly sensitive to the differences between them. Although Gibson (1969), a major proponent of this approach, did not provide a mechanism by which this could occur, such stimulus differentiation can be produced by self-organizing networks (Saksida, 1999). A different approach, advocated by McLaren and Mackintosh, is based on the reduction of salience of common features (e.g., McLaren, Kaye, \& Mackintosh, 1989; McLaren \& Mackintosh, 2000). They used an LI process, based on reduction of attention to passively exposed stimuli, to account for improved performance on a discrimination task. As an example, consider two contexts, $\mathrm{X}$ and $\mathrm{Y}$, each composed of a number of stimulus elements. Some of these elements are common to $\mathrm{X}$ and $\mathrm{Y}$, and some are not. Obviously, the discrimination between $\mathrm{X}$ and $\mathrm{Y}$ depends on their relative percentages of common and different elements. Thus, discrimination between Contexts $\mathrm{X}$ and $\mathrm{Y}$ may be facilitated by the LI of their common elements.

As applied to the context differentiation hypothesis, lengthy exposure to the nominally identical retention interval contexts in the same condition, AA(A)A, would produce the strongest LI effect to the most common stimuli among the stages (since LI is a function of amount of stimulus preexposure), thereby increasing the perceptual difference among the remaining stimuli (i.e., those internal physiological and external background stimuli that spontaneously change over time; see, e.g., Spear, 1978). By definition, this is a time-dependent process, in which the greater the duration of exposure to $(\mathrm{A})$, the greater the effect. Thus, when (A) is of long, but not of short, duration, LI is attenuated, because after a long (A) the test context is perceptually more different from the preexposure context than after a short (A). On the other hand, the AA(B)A condition precludes the reduction of salience of common elements and the ensuing increase in differentiation between preexposure and test contexts. In addition, however, (B) provides a baseline for computing the perceived difference between preexposure and test contexts, such that with increasing time spent in (B), the contexts of preexposure and test become perceptually more similar. Although, admittedly, this description falls short of providing an underlying mechanism, it is readily testable in a variety of experimental paradigms, including those in which simple similarity judgments are used.

Admittedly, the concept of similarity, perceived or objective, is not without its problems (see, e.g., Medin, Goldstone, \& Gentner, 1993). Indeed, the present analysis uses similarity as both a consequence and a cause. On the one hand, perceived similarity of preexposure and test contexts is a function of time between presentations of the two con- 
texts and where that time is spent. On the other hand, the perceived similarity affects behavior, as with LI and SR. A major challenge within the present research domain would be to specify the stimulus dimensions and the combinatorial rules that control the perceptions of similarity of contexts.

In the meantime, we note that it is a generally accepted psychological premise that the similarity of two or more perceptual structures is related to the context in which they are presented (e.g., Goldstone \& Barsalou, 1998; Tversky, 1977). To this, we have added a set of data, until now unavailable, that suggests that the perceptual similarities of contexts, themselves, are not static but that they depend on the physical and temporal relationship between the retention interval context and the acquisition contexts.

\section{Super-LI and Theories of LI}

The fact that the context-dependent, time-induced modulations of LI cannot be explained by simple changes in strength of only one of the two associations (CS-0, CS-US) would seem to support a competition retrieval type of explanation of these effects and, by extension, of LI in general. However, such a position need not discount the possibility that Stage 1 stimulus preexposures also affect the acquisition of the Stage 2 association, as is proposed by the attention/acquisition deficit theories of LI. Indeed, the latter viewpoint is supported by a number of considerations. (1) LI has been obtained with two-stage procedures, in which the second stage has been both CSUS acquisition and test (e.g., Lubow, Markman, \& Allen, 1968; Lubow \& Moore, 1959). Furthermore, in many cases of two-stage LI, the LI effect has appeared from Trial 1 onward (for a review, see Lubow, 1989), which, again, suggests reduced associability of the preexposed stimulus (a failure of acquisition itself, rather than a failure of retrieval from acquisition). (2) Inconsequential preexposure of a stimulus can produce LI after pairing with either appetitive or aversive events. (3) Similarly, LI can be obtained when the same preexposed stimulus is subsequently trained as either a conditioned excitor or a conditioned inhibitor (the preexposed stimulus signals the absence of a reinforcer; see, e.g., Best, 1975; Halgren, 1974; Reiss \& Wagner, 1972; Rescorla, 1971). In regard to 2 and 3 above, "It seems awkward to suppose that preexposure changes such an array of separate, and conflicting, associative strengths" (Rescorla, 2002, p. 370). (4) Rescorla (2002) also examined LI with a procedure designed to differentiate between initial associative strength and retardation of the acquisition of associative strength (associability). Stimulus preexposure affected the rate of subsequent associative learning, but not the initial associative strength. This "supports the common interpretation that latent inhibition involves the reduction in salience of a stimulus, slowing any associative learning in which it is subsequently asked to engage" (Rescorla, 2002, p. 376).

Despite the evidence pointing to the involvement of attention/associability deficit processes in LI, especially in two-stage preparations, such models, by themselves, cannot account for the bidirectional context-dependent, time-induced modulations of LI in three-stage procedures. On the other hand, retrieval competition theory is particularly applicable to the analysis of data from the three-stage LI procedures, because at the time of test there are two potentially competing associations (CS-0 and CS-US). Nevertheless, given that the three-stage procedure incorporates the basic elements of the two-stage procedure, it would seem reasonable to conclude that any explanation of three-stage LI data must make reference to both retrieval competition and attentional/associative deficit processes. However, as we have shown, these models, even if integrated, still remain insufficient to explain the bidirectional modulations of LI. The context differentiation hypothesis, which proposes that perceived changes in context similarity are dependent on the passage of time and where that time is spent, provides a way to account for such results. Notably, the hypothesis is compatible with the retrieval competition and attentional/associative deficit explanations of LI.

\section{CONCLUSIONS}

In summary, the expression of prior learning of two (or more) related events would appear to depend not only on what is learned, but also on the order in which they were learned, the time between learning and testing, and most surprisingly, on where that time was spent. If there are objectively similar contexts across stages (the same physical context, A), then $\mathrm{A}_{1} \mathrm{~A}_{2}$ (long A) $\mathrm{A}_{3}$ context conditions should promote differentiation between $\mathrm{A}_{3}$ and $\mathrm{A}_{1}$ (as well as between $A_{1}$ and $A_{2}$ ), and such a perceived context change would attenuate $\mathrm{LI}$. If the retention interval context is different (B) from the other contexts, then $A_{1}$ $\mathrm{A}_{2}$ (long $\mathrm{B}$ ) $\mathrm{A}_{3}$ context conditions promote context generalization from $A_{3}$ to $A_{1}$ (as well as between $A_{1}$ and $A_{2}$ ), and such an increase in similarity between preexposure and test contexts would potentiate LI. A more general rule can be stated as follows: When two (or more) contexts are similar, an additional context that is different from them accentuates their perceived similarity. However, when two (or more) contexts are similar and the third context also is similar to them, their perceived similarity is decreased. Both effects should increase with the length of time spent in the third context.

This time-induced context differentiation proposal was developed from LI CTA data and applied to the relatively unattended background contexts, rather than to similarity judgments of to-be-chosen, attended targets. It remains to be determined whether this analysis of a unique data set has a more wide-ranging application. If it is more generally true that certain conditions of objective difference can increase perceived similarities and that certain conditions of objective similarity can increase perceived differences, there are, indeed, broader implications. Independently of the explanation and applications of the reported effects, the fact that LI can be either decreased or increased de- 
pending on the retention interval duration and its context would appear to require major modifications of theories of learning and memory.

The river of time, as so aptly described by Marcus Aurelius, also contains shoals and rapids, bends and banks, and when voyaging on uncharted waters, as with the future, you know little of what cargo accompanies you. When the ship unloads, what you find depends not only on what has been stored, but also on where you have been since then and how long ago.

\section{REFERENCES}

Aguado, L., De Brugada, I., \& Hall, G. (2001). Tests for inhibition after extinction of a conditioned stimulus in the flavour aversion procedure. Quarterly Journal of Experimental Psychology, 54B, 201-217.

Aguado, L., Symonds, M., \& Hall, G. (1994). Interval between preexposure and test determines the magnitude of latent inhibition: Implications for an interference account. Animal Learning \& Behavior, 22, 188-194.

Álvarez, R., \& López, M. (1995). Effects of elements or compound preexposure on conditioned taste aversion as a function of retention interval. Animal Learning \& Behavior, 23, 391-399.

Anscombe, F. (1987). The disorder of consciousness in schizophrenia. Schizophrenia Bulletin, 13, 241-260.

Bakner, L., Strohen, K., Nordeen, M., \& Riccio, D.C. (1991). Postconditioning recovery from the latent inhibition effect in conditioned taste aversion. Physiology \& Behavior, 50, 1269-1272.

Baruch, I., Hemsley, D. R., \& Gray, J. A. (1988a). Differential performance of acute and chronic schizophrenics in a latent inhibition task. Journal of Nervous \& Mental Disease, 176, 598-606.

Baruch, I., Hemsley, D. R., \& GRAY, J. A. (1988b). Latent inhibition and "psychotic proneness" in normal subjects. Personality \& Individual Differences, 9, 777-783.

BAtSEll, W. R., JR., \& Best, M. R. (1992a). Investigation of replacement fluids and retention-interval effects in taste-aversion learning. Bulletin of the Psychonomic Society, 30, 414-416.

Batsell, W. R., JR., \& Best, M. R. (1992b). Variations in the retention of taste aversions: Evidence for retrieval competition. Animal Learning \& Behavior, 20, 146-159.

Batsell, W. R., JR., \& Best, M. R. (1993). One bottle too many? Method of testing determines the detection of overshadowing and retention of taste aversions. Animal Learning \& Behavior, 21, 154-158.

BAtsell, W. R., JR., \& Best, M. R. (1994). The role of US novelty in retention interval effects in single-element taste-aversion learning. Animal Learning \& Behavior, 22, 332-340.

Best, M. R. (1975). Conditioned and latent inhibition in taste aversion learning: Clarifying the role of learned safety. Journal of Experimental Psychology: Animal Behavior Processes, 104, 97-113.

Best, M. R., Domjan, M., \& Haskins, W. L. (1978). Long-term retention of flavor familiarization: Effects of number and amount of prior exposures. Behavioral \& Neural Biology, 23, 95-99.

Biederman, G. B., Milgram, N. W., Heighington, G. A., Stockman, S. M., \& O'NeILL, W. (1974). Memory of conditioned food aversion follows a U-shape function in rats. Quarterly Journal of Experimental Psychology, 26, 610-615.

Bouton, M. E. (1991). Context and retrieval in extinction and in other examples of interference in simple associative learning. In L. Dachowski \& C. E. Flaherty (Eds.), Current topics in animal learning: Brain, emotion, and cognition (pp. 25-53). Hillsdale, NJ: Erlbaum.

Bouton, M. E. (1993). Context, time, and memory retrieval in the interference paradigms of Pavlovian learning. Psychological Bulletin, 114, 80-99.

Bouton, M. E. (2002). Context, ambiguity, and unlearning: Sources of relapse after behavioral extinction. Biological Psychiatry, 52, 976-986.

Bouton, M. E. (2004). Context and behavioral processes in extinction. Learning \& Memory, 1, 485-494.

Bouton, M. E., \& Brooks, D. C. (1993). Time and context effects on performance in a Pavlovian discrimination reversal. Journal of Experimental Psychology: Animal Behavior Processes, 19, 165-179.

Bouton, M. E., \& KInG, D. A. (1983). Contextual control of the extinction of conditioned fear: Tests for the associative value of the context. Journal of Experimental Psychology: Animal Behavior Processes, 9, 248-265.

Bouton, M. E., Nelson, J. B., \& Rosas, J. M. (1999). Stimulus generalization, context change, and forgetting. Psychological Bulletin, 125, 171-186.

Bouton, M. E., \& Peck, C. A. (1989). Context effects on conditioning, extinction, and reinstatement in an appetitive conditioning preparation. Animal Learning \& Behavior, 17, 188-198.

Bouton, M. E., \& PeCK, C. A. (1992). Spontaneous recovery in crossmotivational transfer (counterconditioning). Animal Learning \& Behavior, 20, 313-321.

Brooks, D. C., \& Bouton, M. E. (1993). A retrieval cue for extinction attenuates spontaneous recovery. Journal of Experimental Psychology: Animal Behavior Processes, 19, 77-89.

Chiszar, D. A., \& Spear, N. E. (1969). Stimulus change, reversal learning, and retention in the rat. Journal of Comparative \& Physiological Psychology, 69, 190-195.

De la Casa, L. G., Diaz, E., \& Lubow, R. E. (2003). Effects of posttreatment retention interval and context on neophobia and conditioned taste aversion. Behavioural Processes, 63, 159-170.

De la Casa, L. G., Diaz, E., \& Lubow R. E. (2005). Delay-induced attenuation of latent inhibition with a conditioned emotional response depends on CS-US strength. Learning \& Motivation, 36, 60-76.

De la Casa, L. G., \& Lubow, R. E. (1995). Latent inhibition in conditioned taste aversion: The roles of stimulus frequency and duration and the amount of fluid ingested during preexposure. Neurobiology of Learning \& Memory, 64, 125-132.

De la Casa, L. G., \& Lubow, R. E. (2000). Super-latent inhibition with delayed conditioned taste aversion testing. Animal Learning \& Behavior, 28, 389-399.

De la Casa, L. G., \& Lubow, R. E. (2002). An empirical analysis of the super-latent inhibition effect. Animal Learning \& Behavior, 30, 112-120.

De la CASA, L. G., \& Lubow, R. E. (2005). Delay-induced super-latent inhibition as a function of order of exposure to two flavors prior to compound conditioning. Quarterly Journal of Experimental Psychology, 58B, 1-18.

Escobar, M., Arcediano, F., \& Miller, R. R. (2002). Latent inhibition and contextual associations. Journal of Experimental Psychology: Animal Behavior Processes, 28, 123-136.

Escobar, M., Oberling, P., \& Miller, R. R. (2002). Associative deficit accounts of disrupted latent inhibition and blocking in schizophrenia. Neuroscience \& Biobehavioral Reviews, 26, 203-216.

EsTes, W. K, (1997). Processes of memory loss, recovery, and distortion. Psychological Review, 104, 148-169.

Fresquet, N., Yamamoto, J., \& Sandner, G. (2003). Frontal lesions do not alter the differential extinction of taste aversion conditioning in rats, using two methods of sucrose delivery. Behavioural Brain Research, 141, 25-34.

Gibson, E. J. (1969). Principles of perceptual learning and development. New York: Appleton-Century-Crofts.

Gleitman, H. (1971). Forgetting of long-term memories in animals. In W. K. Honig \& P. H. R. James (Eds.), Animal memory (pp. 1-44). San Diego: Academic Press.

Goldstone, R. L., \& Barsalou, L. W. (1998). Reuniting perception and conception. Cognition, 65, 231-262.

Gordon, W. C., \& SPEAR, N. E. (1973). Effect of reactivation of a previously acquired memory on the interaction between memories in the rat. Journal of Experimental Psychology, 99, 349-355.

Grahame, N. J., Barnet, R. C., Gunther, L. M., \& Miller, R. R. (1994). Latent inhibition as a performance deficit resulting from CScontext associations. Animal Learning \& Behavior, 22, 395-408.

GrAY, J. A. (1998). Integrating schizophrenia. Schizophrenia Bulletin, 24, 249-266.

Gray, J. A., Feldon, J., Rawlins, J. N. P., Hemsley, D. R., \& Smith, A. D. (1991). The neuropsychology of schizophrenia. Behavioral \& Brain Sciences, 14, 1-84. 
Gray, N. S., Hemsley, D. R., \& Gray, J. A. (1992). Abolition of latent inhibition in acute, but not chronic, schizophrenics. Neurology, Psychiatry \& Brain Research, 1, 83-89.

HALGREN, C. R. (1974). Latent inhibition in rats: Associative or nonassociative? Journal of Comparative \& Physiological Psychology, 86, 74-78.

Hall, G. (1991). Perceptual and associative learning. Oxford: Oxford University Press, Clarendon Press.

Hall, G., \& Channell, S. (1985). Differential effects of contextual change on latent inhibition and on the habituation of an orienting response. Journal of Experimental Psychology: Animal Behavior Processes, 11, 470-481.

Hall, G., \& Honey, R. C. (1989). Contextual effects in conditioning, latent inhibition, and habituation-associative and retrieval functions of contextual cues. Journal of Experimental Psychology: Animal Behavior Processes, 15, 232-241.

Hall, G., \& Schachtman, T. R. (1987). Differential effects of a retention interval on latent inhibition and the habituation of an orienting response. Animal Learning \& Behavior, 15, 76-82.

Harris, J. A., Jones, M. L., Bailey, G. K., \& Westbrook, R. F. (2000). Contextual control over conditioned responding in an extinction paradigm. Journal of Experimental Psychology: Animal Behavior Processes, 26, 174-185.

Honey, R. C., Pye, C., Lightbrown, Y., Rey, V., \& Hall, G. (1992). Contextual factors in neophobia and its habituation: The role of absolute and relative novelty. Quarterly Journal of Experimental Psychology, 45B, 327-347.

IshiI, K., Yamada, Y., Hishimura, Y., \& HaGa, Y. (2002). The effects of preexposure-test and conditioning-test intervals on the magnitude of latent inhibition. Japanese Psychological Research, 44, 51-56.

Kasprow, W. J., Catterson, D., Schachtman, T. R., \& Miller, R. R. (1984). Attenuation of latent inhibition by postacquisition reminder. Quarterly Journal of Experimental Psychology, 36B, 53-63.

Kaye, H., Gambini, B., \& Mackintosh, N. J. (1988). A dissociation between one-trial overshadowing and the effect of a distractor on habituation. Quarterly Journal of Experimental Psychology, 40B, 31-47.

Killcross, [A.] S., \& BALleine, B. (1996). Role of primary motivation in stimulus preexposure effects. Journal of Experimental Psychology: Animal Behavior Processes, 22, 32-42.

Killcross, A. S., Kiernan, M. J., Dwyer, D., \& Westbrook, R. F. (1998). Effects of retention interval on latent inhibition and perceptual learning. Quarterly Journal of Experimental Psychology, 51B, 59-74.

KinTSCH, W., \& Mross, E. F. (1985). Context effects in word identification. Journal of Memory \& Language, 24, 336-349.

Knoedler, A. J., Hellwig, K. A., \& Neath, I. (1999). The shift from recency to primacy with increasing delay. Journal of Experimental Psychology: Learning, Memory, \& Cognition, 25, 474-487.

KonORSKI, J., \& SzWEJKowsKa, G. (1952). Chronic extinction and restoration of conditioned reflexes: IV. The dependence of the course of extinction and restoration of conditioned reflexes on the "history" of the conditioned stimulus (The principle of the primacy of first training). Acta Biologiae Experimentalis, 16, 95-113.

Kraemer, P. J., \& OssenKopP, K.-P. (1986). The effects of flavor preexposure and test interval on conditioned taste aversions in rats. Bulletin of the Psychonomic Society, 24, 219-221.

Kraemer, P. J., Randall, C. K., \& Carbary, T. J. (1991). Release from latent inhibition with delayed testing. Animal Learning \& Behavior, 19, 139-145.

Kraemer, P. J., \& Roberts, W. A. (1984). The influence of flavor preexposure and test interval on conditioned taste aversion in the rat. Learning \& Motivation, 15, 259-278.

Kraemer, P. J., \& Spear, N. E. (1992). The effect of nonreinforced stimulus exposure on the strength of a conditioned taste aversion as a function of retention interval: Do latent inhibition and extinction involve a shared process? Animal Learning \& Behavior, 20, 1-7.

Lovibond, P. F., Preston, G. C., \& Mackintosh, N. J. (1984). Context specificity of conditioning, extinction, and latent inhibition. Journal of Experimental Psychology: Animal Behavior Processes, 10, 360-375.
Lubow, R. E. (1973). Latent inhibition. Psychological Bulletin, 79, 398407.

LuBow, R. E. (1989). Latent inhibition and conditioned attention theory. New York: Cambridge University Press.

LuBow, R. E. (1998). Latent inhibition and behavioral pathology: Some effects of stimulus preexposure. In W. O'Donohue (Ed.), Learning and behavior therapy (pp. 107-121). Boston: Allyn \& Bacon.

LuBow, R. E. (2005). The construct validity of the animal latent inhibition model of selective attention deficits in schizophrenia. Schizophrenia Bulletin, 31, 139-153.

Lubow, R. E., \& De la Casa, L. G. (2002). Superlatent inhibition and spontaneous recovery: Differential effects of pre- and postconditioning CS-alone presentations after long delays in different contexts. Animal Learning \& Behavior, 30, 376-386.

Lubow, R. E., \& De LA CASA, L. G. (2005). Time-induced super-latent inhibition is dependent on the distinctiveness of the retention-interval context from the other experimental contexts. Learning \& Motivation, 36, 322-330.

Lubow, R. E., \& Gewirtz, J. C. (1995). Latent inhibition in humans: Data, theory, and implications for schizophrenia. Psychological Bulletin, 117, 87-103.

Lubow, R. E., Ingberg-Sachs, Y., Zalstein-Orda, N., \& Gewirtz, J. C. (1992). Disruption of latent inhibition in high psychotic-prone normal subjects. Personality \& Individual Differences, 13, 563-572.

LuBOw, R. E., \& KaPLAN, O. (2005). The visual search analogue of latent inhibition: Implications for theories of irrelevant stimulus processing in normal and schizophrenic groups. Psychonomic Bulletin \& Review, 12, 224-243.

Lubow, R. E., Markman, R. E., \& Allen, J. (1968). Latent inhibition and classical conditioning of the rabbit pinna response. Journal of Comparative \& Physiological Psychology, 66, 688-694.

Lubow, R. E., \& Moore, A. U. (1959). Latent inhibition: The effect of nonreinforced preexposure to the to-be-conditioned stimulus. Journal of Comparative \& Physiological Psychology, 52, 416-419.

Lubow, R. E., Rifkin, B., \& Alek, M. (1976). The context effect: The relationship between stimulus preexposure and environmental preexposure determines subsequent learning. Journal of Experimental Psychology: Animal Behavior Processes, 2, 38-47.

Lubow, R. E., WeIner, I., \& Schnur, P. (1981). Conditioned attention theory. In G. H. Bower (Ed.), The psychology of learning and motivation (Vol. 15, pp. 1-49). New York: Academic Press.

Mackintosh, N. J. (1975). A theory of attention: Variations in the associability of stimuli with reinforcement. Psychological Review, 82, 276-298.

McGeoch, J. A. (1942). The psychology of human learning: An introduction. New York: Longmans, Green.

Mclaren, I. P. L., Bennett, C., Plaisted, K., Aitken, M., \& MacKINTOSH, N. J. (1994). Latent inhibition, context specificity, and context familiarity. Quarterly Journal of Experimental Psychology, 47B, 387-400.

McLaren, I. P. L., Kaye, H., \& Mackintosh, N. J. (1989). An associative theory of the representation of stimuli: Applications to perceptual learning and latent inhibition. In R. G. M. Morris (Ed.), Parallel distributed processing: Implications for psychology and neurobiology (pp. 102-130). New York: Oxford University Press.

McLaren, I. P. L., \& Mackintosh, N. J. (2000). An elemental model of associative learning: I. Latent inhibition and perceptual learning. Animal Learning \& Behavior, 28, 211-246.

Medin, D. L., Goldstone, R. L., \& Gentner, D. (1993). Respects for similarity. Psychological Review, 100, 254-278.

Mensink, G., \& RaAiJmakers, J. G. W. (1988). A model for interference and forgetting. Psychological Review, 95, 434-455.

MiLler, R. R., \& Escobar, M. (2002). Associative interference between cues and between outcomes presented together and presented apart: An integration. Behavioural Processes, 57, 163-185.

Miller, R. R., Kasprow, W. J., \& Schachtman, T. R. (1986). Retrieval variability: Sources and consequences. American Journal of Psychology, 99, 145-218.

Miller, R. R., \& MATzEL, L. D. (1988). The comparator hypothesis: A response rule for the expression of associations. In G. H. Bower (Ed.), 
The psychology of learning and motivation (Vol. 22, pp. 51-92). New York: Academic Press.

Mirsky, A. F., \& Duncan, C. C. (1986). Etiology and expression of schizophrenia: Neurobiological and psychosocial factors. Annual Review of Psychology, 37, 291-319.

Nelson, J. B. (2002). Context specificity of excitation and inhibition in ambiguous stimuli. Learning \& Motivation, 33, 284-310.

Nuechterlein, K. H., \& Dawson, M. E. (1984). Information processing and attentional functioning in the developmental course of the schizophrenic disorder. Schizophrenia Bulletin, 10, 160-203.

Oberling, P., Gosselin, O., \& Miller, R. R. (1998). Latent inhibition in animals as a model of acute schizophrenia: A re-analysis. In M. Haug \& R. E. Whalen (Eds.), Animal models of human emotion and cognition (pp. 87-102). Washington, DC: American Psychological Association.

Otтo, T., Cousens, G., \& Rajewski, K. (1997). Odor-guided fear conditioning in rats: 1 . Acquisition, retention, and latent inhibition. $B e$ havioral Neuroscience, 111, 1257-1264.

PAYNe, D. G. (1987). Hypermnesia and reminiscence in recall: A historical and empirical review. Psychological Bulletin, 101, 5-27.

Pearce, J. M., \& Hall, G. (1980). A model for Pavlovian conditioning: Variations in the effectiveness of conditioned but not unconditioned stimuli. Psychological Review, 87, 332-352.

Peck, C. A., \& Bouton, M. E. (1990). Context and performance in aversive-to-appetitive and appetitive-to-aversive transfer. Learning \& Motivation, 21, 1-31.

Postman, L., Stark, K., \& Fraser, J. (1968). Temporal changes in interference. Journal of Verbal Learning \& Verbal Behavior, 7, 672-694.

Reed, P., Croft, H., \& Yeomans, M. (1996). Rats' memory for serially presented novel flavours: Evidence for non-spatial primacy effects. Quarterly Journal of Experimental Psychology, 49B, 174-187.

Reiss, S., \& WAGNER, A. R. (1972). CS habituation produces a "latent inhibition effect" but no active "conditioned inhibition." Learning \& Motivation, 3, 237-245.

RESCORLA, R. A. (1971). Summation and retardation tests of latent inhibition. Journal of Comparative \& Physiological Psychology, 75, 77-81.

Rescorla, R. A. (1997). Spontaneous recovery after Pavlovian conditioning with multiple outcomes. Animal Learning \& Behavior, 25, 99-107.

Rescorla, R. A. (2002). Savings tests: Separating differences in rate of learning from differences in initial levels. Journal of Experimental Psychology: Animal Behavior Processes, 28, 369-377.

Riccio, D. C., Ackil, J., \& Burch-Vernon, A. (1992). Forgetting of stimulus attributes: Methodological implications for assessing associative phenomena. Psychological Bulletin, 112, 433-445.

Riccio, D. C., Rabinowitz, V. C., \& Axelrod, S. (1994). Memory: When less is more. American Psychology, 49, 917-926.

Riccio, D. C., Richardson, R., \& Ebner, D. L. (1984). Memory retrieval deficits based upon altered contextual cues: A paradox. Psychological Bulletin, 96, 152-165.

Rosas, J. M., \& Bouton, M. E. (1996). Spontaneous recovery after extinction of a conditioned taste aversion. Animal Learning \& Behavior, 24, 341-348.

Rosas, J. M., \& Bouton, M. E. (1997). Additivity of the effects of retention interval and context change on latent inhibition: Toward resolution of the context forgetting paradox. Journal of Experimental Psychology: Animal Behavior Processes, 23, 283-294.

Rosas, J. M., \& Bouton, M. E. (1998). Context change and retention interval can have additive, rather than interactive, effects after taste aversion extinction. Psychonomic Bulletin \& Review, 5, 79-83.

Rosas, J. M., Vila, J., Lugo, M., \& Lopez, L. (2001). Combined effect of context change and retention interval on interference in causality judgments. Journal of Experimental Psychology: Animal Behavior Processes, 27, 153-164.

Rubin, D. C., \& Wenzel, A. E. (1996). One hundred years of forgetting: A quantitative description of retention. Psychological Review, 103, 734-760.

SAKSIDA, L. M. (1999). Effects of similarity and experience on discrimi- nation learning: A nonassociative connectionist model of perceptual learning. Journal of Experimental Psychology: Animal Behavior Processes, 25, 308-323.

SiEgEL, S. (1974). Flavor preexposure and "learned safety." Journal of Comparative \& Physiological Psychology, 87, 1073-1082.

Smith, S. M., Glenberg, A., \& Bjork, R. A. (1978). Environmental context and human memory. Memory \& Cognition, 6, 342-353.

Spear, N. E. (1973). Retrieval of memory in animals. Psychological Review, 80, 163-194.

SPEAR, N. E. (1978). The processing of memories: Forgetting and retention. Hillsdale, NJ: Erlbaum.

Spear, N. E., Smith, G. H., Bryan, R. G., Gordon, W. C., Timmons, R., \& ChiszaR, D. A. (1980). Contextual influences on the interaction between conflicting memories in the rat. Animal Learning \& Behavior, 8, 273-281.

Steinert, P. A., Infurna, R. N., \& Spear, N. E. (1980). Long-term retention of a conditioned taste aversion in preweanling and adult rats. Animal Learning \& Behavior, 8, 375-381.

Stout, S. C., Amundson, J. C., \& Miller, R. R. (in press). Trial order and retention interval in human predictive judgment. Memory \& $\mathrm{Cog}$ nition.

Tversky, A. (1977). Features of similarity. Psychological Review, 84, 327-352.

UNDERWOOD, B. J. (1948a). Retroactive and proactive inhibition after five and forty-eight hours. Journal of Experimental Psychology, 38, 29-38.

UNDERWOOD, B. J. (1948b). "Spontaneous recovery" of verbal associations. Journal of Experimental Psychology, 38, 429-439.

Urushimara, K., Wheeler, D. S., \& Miller, R. R. (2004). Outcome pre- and postexposure effects: Retention interval interacts with primacy and recency. Journal of Experimental Psychology: Animal Behavior Processes, 30, 283-298.

Vila, J., Romero, M., \& Rosas, J. M. (2002). Retroactive interference after discrimination reversal decreases following temporal and physical context changes in human subjects. Behavioural Processes, 59, 47-54.

WAGNER, A. R. (1981). SOP: A model of automatic memory processing in animal behavior. In N. E. Spear \& R. R. Miller (Eds.), Information processing in animals: Memory mechanisms (pp. 5-47). Hillsdale, NJ: Erlbaum.

Weiner, I. (2003). The "two-headed" latent inhibition model of schizophrenia: Modeling positive and negative symptoms and their treatment. Psychopharmacology, 169, 257-297.

Westbrook, R. F., Jones, M. L., Bailey, G. K., \& Harris, J. A. (2000). Contextual control over conditioned responding in a latent inhibition paradigm. Journal of Experimental Psychology: Animal Behavior Processes, 26, 157-173.

Wheeler, D. S., Stout, S. C., \& Miller, R. R. (2004). Interaction of retention interval with CS-preexposure and extinction treatments: Symmetry with respect to primacy. Learning \& Behavior, 32, 335-347.

Wickens, C., Tuber, D. S., \& Wickens, D. D. (1983). Memory for the conditioned response: The proactive effect of preexposure to potential conditioning stimuli and context change. Journal of Experimental Psychology: General, 112, 41-57.

Wright, A. A., Santiago, H. C., Sands, S. F., Kendrick, D. F., \& Cook, R. G. (1985). Memory processing of serial lists by pigeons, monkeys, and people. Science, 229, 287-289.

\section{NOTES}

1. Table 1 refers only to CTA experiments that manipulated delays between acquisition and test stages. There also are studies that have varied the delay between preexposure and acquisition stages, but with inconsistent results. Aguado et al. (1994, Experiment 3) reported reduced LI after a 12-day delay. However, De la Casa and Lubow (2002, Experiment 3) found intact LI after a 21-day delay. Rosas and Bouton (1997), with a 28-day delay, observed intact LI in Experiment 1 but attenuated $\mathrm{LI}$ in Experiment 2 in the absence of any critical procedural differences between experiments. 
2. The primacy principle may reflect the same processes involved in the primacy/recency effects reported in the animal and human memory literature, where one can also find a shift from recency to primacy with an increase in retention interval (e.g., Knoedler, Hellwig, \& Neath, 1999; Wright, Santiago, Sands, Kendrick, \& Cook, 1985). However, the retention intervals in these studies were on the order of seconds and minutes.

3. On Days 13-20, animals in 21-day delay groups have continuous access to water. On Day 21, the water deprivation schedule is reinstated, thus ensuring that the subjects in both delay conditions have the same deprivation level at test as on the conditioning day. After each experimental session, the animals receive water in their home cages for $25 \mathrm{~min}$.

4. The Rosas and Bouton (1997) study is not included here, since the retention interval preceded a combined acquisition-test session.
5. Although it is well established that a change of context from the preexposure stage to the acquisition or test stage attenuates LI, the context differentiation proposal leads to the prediction that LI will be reinstated if there is a long delay that is spent in a different context from that of the other experimental stages. As was suggested, such a delay should increase the similarity of the contexts of the other stages and, thereby, promote LI. Indeed, the context differentiation hypothesis suggests a number of counterintuitive predictions in a variety of research domains.

(Manuscript received November 24, 2004; revision accepted for publication April 12, 2005.) 